\title{
HETEROTOPIC CARDIAC TRANSPLANTATION IN INFANTS AND CHILDREN
}

Asghar Khaghani, FRCS

Francesco Santini, MD

Cornelius M. Dyke, MD

Obed Onuzu, MRCP

Rosemary Radley-Smith, FRCP

Magdi H. Yacoub, FRCS
Background: Children with advanced heart failure, particularly those with elevated pulmonary vascular resistance, pose a difficult management problem because the normal donor right ventricle cannot cope with the high pulmonary resistance and because of the relative shortage of donor organs of an appropriate size for this age group. Methods: In an attempt to address these issues and evaluate the role of heterotopic transplantation in this context, we operated on 12 children, six boys and six girls, in the period between January 1, 1991, and March 31, 1996. Their ages ranged from 11 months to 15.2 years (mean $81.6 \pm 62.8$ months) and their mean weight was $23.3 \mathrm{~kg}$ (range 7.6 to $56.8 \mathrm{~kg}$ ). Eight patients $(66.6 \%$ ) had significant elevation of pulmonary artery pressure (pulmonary artery systolic pressure $=66 \pm 9.4 \mathrm{~mm} \mathrm{Hg}$, mean transpulmonary gradient $=22.3 \pm 3.4 \mathrm{~mm}$ $\mathrm{Hg}$ ). In all patients the donor pulmonary artery was anastomosed to the recipient right atrium without the use of any prosthetic material. Ischemic times varied between 135 and 255 minutes (mean $182.1 \pm 30.7$ minutes). The immunosuppression regimen included cyclosporine and azathioprine. Steroids were not routinely used. Results: One patient died in the hospital of acute rejection on postoperative day 16. Three patients had lobe collapse within 1 week and all were treated successfully. Two late deaths (18.2\%) occurred as a result of cardiac rejection 3 months and 2 years after the operations. Nine survivors $(75 \%)$ are alive, active, and growing normally at a mean follow-up of 2.2 years (range 11 months to 4.75 years). Repeated cardiac catheterization performed in seven patients with preoperative pulmonary hypertension showed a slow progressive drop in mean pulmonary artery pressure. No significant change was observed in the function of the recipient hearts. Conclusion: We conclude that heterotopic heart transplantation is feasible for a selected group of children with good medium-term results, notably regression of pulmonary artery pressure, normal growth, and lack of long-term chest complications. (J Thorac Cardiovasc Surg 1997;113:1042-9)
0 rthotopic heart transplantation is an accepted and effective method for the management of end-stage congestive heart failure. On the contrary, the use of heterotopic heart transplantation is still

From Harefield Hospital, Harefield, Middlesex, United Kingdom.

Read at the Seventy-sixth Annual Meeting of The American Association for Thoracic Surgery, San Diego, Calif., April 28-May 1, 1996.

Received for publication May 6, 1996; revisions requested June 24, 1996; revisions received Jan. 23, 1997; accepted for publication Jan. 23, 1997.

Address for reprints: Asghar Khaghani, FRCS, Harefield Hospital NHS Trust, Harefield, Middlesex, UB9 $6 J \mathrm{H}$, United Kingdom.

Copyright (C) 1997 by Mosby-Year Book, Inc.

$0022-5223 / 97 \$ 5.00+0 \quad \mathbf{1 2 / 6 / 8 0 7 3 6}$ controversial, with only a few reports, particularly in pediatric patients. ${ }^{1-8}$

Children with advanced heart failure, particularly those with elevated pulmonary vascular resistance (PVR), pose a difficult management problem because of the scarcity of suitable organ donors in this age group and the high rate of detrimental right heart failure in the presence of elevated PVR. Waiting time for a suitable orthotopic transplant, especially when a "domino" heart is required, is often excessive and associated with a significant mortality in this age group. ${ }^{8}$ Heart-lung transplantation may be an option in patients with elevated PVR, although recent evidence that obliterative bronchiolitis is prevalent in the pediatric population has presently reduced the enthusiasm for the procedure in this subgroup. ${ }^{9-11}$ 


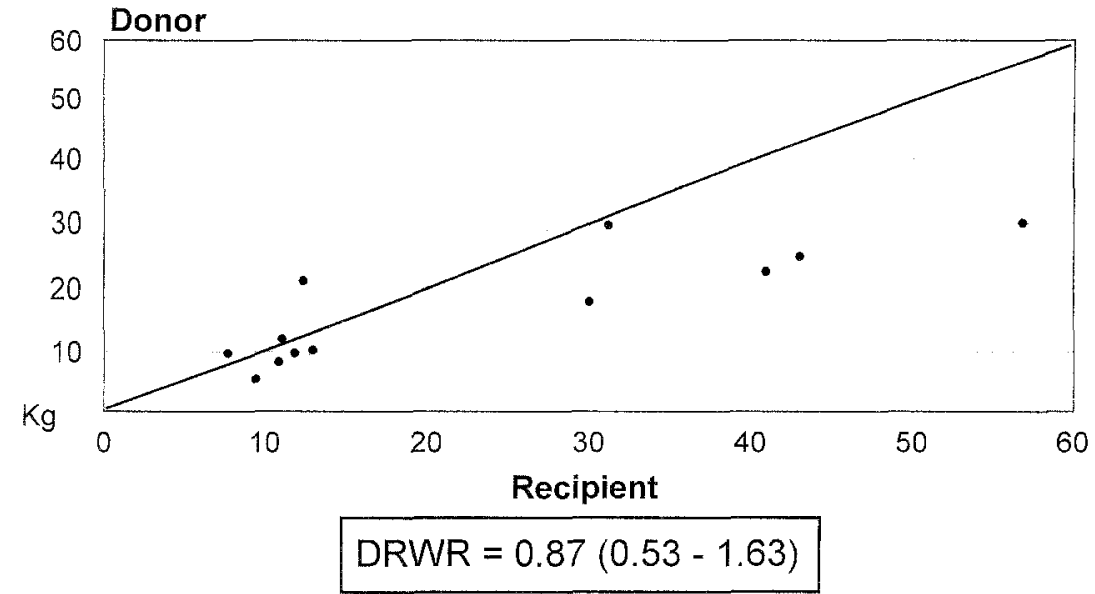

Fig. 1. Matching of donor to recipient body weight. The line of unity represents 1:1 size matching. Three donors were oversized, one significantly. The remainder of the donors were undersized. $D R W R$, Donor/recipient weight ratio.

Table I. Recipient age and weight at operation, recipient hemodynamic data before transplantation, donor age and weight, donor/recipient weight match, hemodynamic result after transplantation, and outcome

\begin{tabular}{|c|c|c|c|c|c|c|c|c|c|c|c|}
\hline \multirow[b]{2}{*}{ Case } & \multicolumn{5}{|c|}{ Recipient data } & \multicolumn{2}{|c|}{ Donor data } & \multicolumn{3}{|c|}{ Late hemodynamic result } & \multirow[b]{2}{*}{ Outcome } \\
\hline & $\begin{array}{l}\text { Age } \\
\text { (mo) }\end{array}$ & $\begin{array}{c}\text { Weight } \\
(\mathrm{kg})\end{array}$ & Diagnosis & $\begin{array}{c}\text { SysPAP } \\
(m m I g)\end{array}$ & $\begin{array}{c}T P G \\
(m m ~ H g)\end{array}$ & $\begin{array}{l}\text { Age } \\
\text { (mo) }\end{array}$ & $\begin{array}{c}\text { Weight } \\
(\mathrm{kg})\end{array}$ & $D R W r$ & $\begin{array}{c}\text { SysPAP } \\
(m m \mathrm{Hg})\end{array}$ & $\begin{array}{c}T P G \\
(m m \mathrm{Hg})\end{array}$ & \\
\hline 1 & 16 & 7.6 & $\mathrm{RCM}$ & 70 & 17 & 11 & 10.3 & 1.36 & 38 & 12 & Alive \\
\hline 2 & 164 & 30 & $\mathrm{RCM}$ & 60 & 23 & 60 & 18 & 0.6 & 22 & 9 & Alive \\
\hline 3 & 37 & 12.1 & $\mathrm{DCM}$ & 80 & 22 & 11 & 10 & 0.83 & 26 & 5 & Alive \\
\hline 4 & 27 & 11 & $\mathrm{DCM}$ & $*$ & * & 24 & 12 & 1.09 & $*$ & $*$ & Dead (early) \\
\hline 5 & 114 & 44 & DCM & 32 & 8 & 108 & 25 & 0.57 & $*$ & $*$ & Alive \\
\hline 6 & 146 & 40.8 & DCM & 43 & 5 & 132 & 23 & 0.56 & $*$ & $*$ & Dead (late) \\
\hline 7 & 46 & 12.5 & $\mathrm{RCM}$ & 64 & 22 & 21 & 10 & 0.8 & 32 & 8 & Alive \\
\hline 8 & 11 & 9.4 & $\mathrm{DCM}$ & 50 & 23 & 5 & 6 & 0.64 & 20 & 6 & Alive \\
\hline 9 & 183 & 56.8 & DCM & 60 & 30 & 108 & 30 & 0.53 & 20 & 6 & Alive \\
\hline 10 & 53 & 12.9 & RCM & 79 & 22 & 54 & 21 & 1.63 & 34 & 12 & Alive \\
\hline 1 & 160 & 31.4 & DCM & 65 & 20 & 120 & 30 & 0.96 & $*$ & $*$ & Dead (late) \\
\hline 12 & 26 & 10.7 & DCM & 26 & 6 & 24 & 10 & 0.93 & $*$ & $*$ & Alive \\
\hline
\end{tabular}

Sys $P A P$, Systolic pulmonary artery pressure; TPG, transpulmonary gradient; $R C M$, restrictive cardiomyopathy; $D C M$, dilated cardiomyopathy; $D R W r$, donor/recipient weight ratio.

*Data not available.

Although heterotopic heart transplantation in children has generally been considered impractical because of the small size of the recipient thoracic cavity ${ }^{8}$ the procedure might be a valuable alternative in selected cases. In an attempt to clarify the possible role of heterotopic heart transplantation in children, we have retrospectively analyzed the experience developed at a single institution with a large transplant volume.

\section{Methods}

Since the beginning of the transplant program at Harefield in 1980 until March 1996, 1278 cardiac trans- plantations have been performed. Of these, 104 were heterotopic heart transplantations, representing $8.1 \%$ of the total experience. Since January 1991, 12 children, six boys and six girls, underwent heterotopic heart transplantation (11.6\% of all recipients of heterotopic hearts). Their ages ranged from 11 months to 15.2 years (mean $81.6 \pm 62.8$ months) and their mean weight was $23.3 \mathrm{~kg}$ (range 7.6 to $56.8 \mathrm{~kg}$ ). The age and weight of the donors were 56.5 months (range 11 months to 10 years) and 17.1 $\mathrm{kg}$ (range 6 to 30), respectively (Table I). Donor/recipient weight ratio ranged between 0.53 and 1.63 , mean 0.87 (Fig. 1). Eight patients had dilated cardiomyopathy and four, restrictive cardiomyopathy. All children had severe congestive heart failure while receiving maximal medical therapy. Indications for heterotopic heart transplantation 


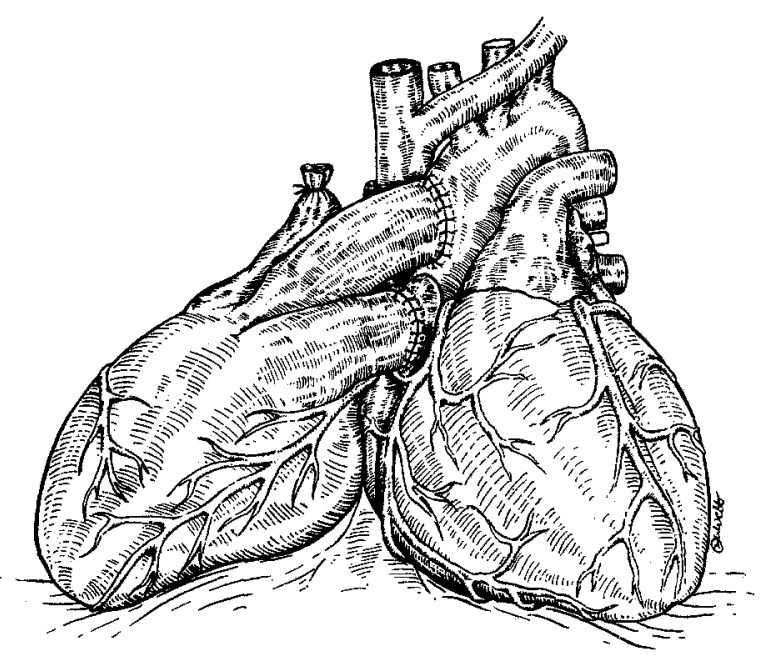

Fig. 2. The completed heterotopic heart transplant. The donor SVC was ligated in patients younger than 5 years old. Note the anastomosis of the donor pulmonary artery to the recipient right atrium.

included a significantly undersized donor (42\%) and the presence of pulmonary hypertension in a recipient with PVR between 4 and 7 Wood units or a transpulmonary gradient above $10 \mathrm{~mm} \mathrm{Hg}$ (eight patients: 66.6\%; pulmonary artery systolic pressure $=66 \pm 9.4 \mathrm{~mm} \mathrm{Hg}$, mean transpulmonary gradient $=22.3 \pm 3.4$ ) (Table I). In two patients $(16.6 \%)$ younger than 2 years old, heterotopic heart transplantation was performed to allow for possible recovery of the recipient heart. Indications for heterotopic heart transplantation overlapped in some cases.

The total mean ischemic time for the donor organ was $182.1 \pm 30.7$ minutes, with a range of 135 to 255 minutes. Mean cardiopulmonary bypass time was $85 \pm 32$ minutes (range 57 to 162 minutes).

Surgical technique. Through a median sternotomy the right pleural space was opened wide and the pericardium was released from the diaphragm down to the inferior vena cava. Aortic and bicaval venous cannulation was used in all cases. The donor heart was harvested with a long segment of the superior vena cava (SVC) and the transverse aortic arch. The donor inferior vena cava was oversewn and the left atrium opened wide by connecting the orifice of the four pulmonary veins. For implantation after establishment of cardiopulmonary bypass, the native heart was fibrillated and the left ventricle vented through a stab wound in the apex. The recipient intraatrial groove was dissected in a fashion similar to the standard mitral valve approach. The donor heart was then placed in the right pleural cavity with the apex to the right, and the left atrium-left atrium anastomosis was constructed with running polypropylene suture. In five patients (42\%), all younger than 5 years old, the donor SVC was ligated; in the remaining seven $(58 \%)$ it was anastomosed to the recipient SVC in an end-to-side fashion and as high as possible on the native SVC, because a high anastomosis

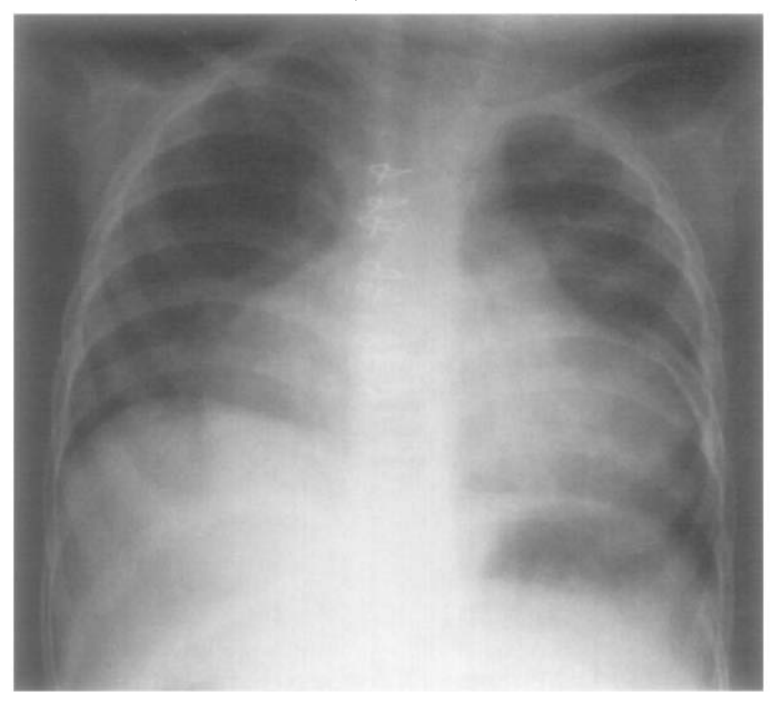

Fig. 3. Representative chest roentgenogram after heterotopic heart transplantation in an infant.

seems to facilitate subsequent donor heart biopsy. The aortic anastomosis was then constructed end to side on the recipient ascending aorta. The recipient heart was continuously perfused throughout the procedure. In all cases the donor pulmonary artery was connected to the recipient right atrium according to the original heterotopic technique first described by Barnard and Losman, ${ }^{12}$ in which the donor heart provides assistance to the left side of the heart only (Fig. 2). Temporary epicardial atrioventricular pacing wires for both donor and recipient hearts and chest tube drainage of the mediastinum and right side of the chest were routinely placed before closure. A typical chest roentgenogram of a patient after the procedure is shown in Fig. 3.

No major problems were related to the limited intrathoracic space except in one patient whose sternum was stented open for 72 hours after the operation to improve cardiac output.

Immunosuppressive therapy. Immunosuppression in the early postoperative period consisted of cyclosporine $A$ and azathioprine with minimal or no steroid use.

Clinical and echocardiographic criteria were used to monitor for acute cardiac rejection. Endomyocardial biopsy was used to confirm acute rejection in selected patients.

Follow-up. Routine monitoring was used in the intensive care unit in the immediate postoperative period. Serial echocardiograms were used to evaluate donor and recipient ventricular performance. In the early postoperative period three patients $(25 \%)$ underwent successful temporary paced linkage of donor and recipient hearts to achieve coordinated contraction of the two organs, with significant hemodynamic improvement. ${ }^{13}$

After discharge, patients were evaluated in the transplant clinic at regular intervals. Cardiac catheterization was performed yearly in most patients.

Statistics. Statistical analysis was performed with the use of commercially available software (Arcus Prostat 


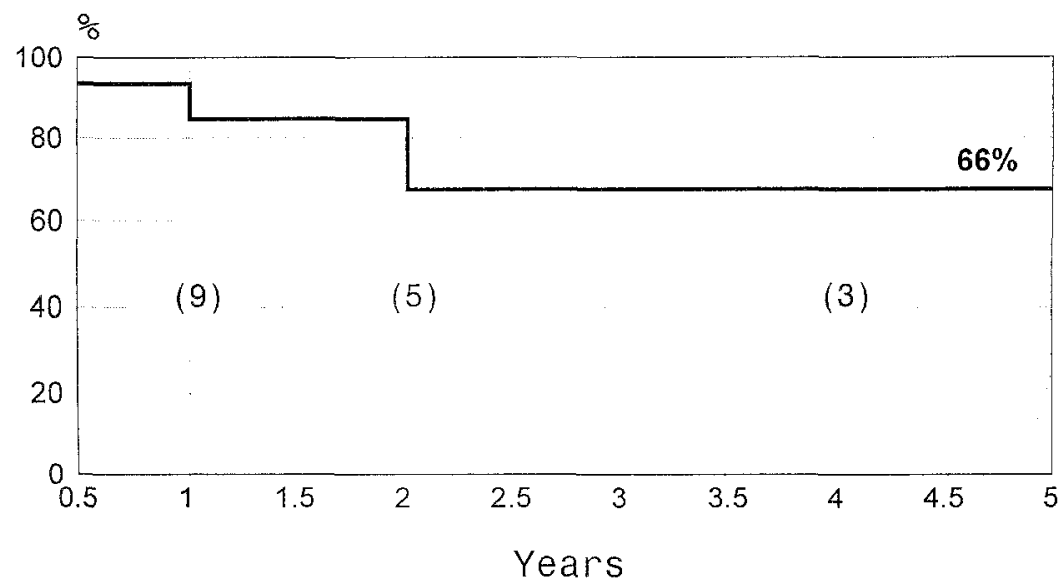

Fig. 4. Actuarial survival curve of pediatric heterotopic transplant recipients. One- and 5-year actuarial survivals were $83 \%$ and $66 \%$, respectively. Numbers of patients at risk at each time point are shown in parentheses.

version 3) (Medical Computing, West Lanes, United Kingdom). All data are given as mean \pm standard deviation unless otherwise expressed.

Actuarial survival curves were calculated according to the method of Kaplan and Meier. ${ }^{14}$ Postoperative data were compared with the baseline by means of a one-way analysis of variance. All $p$ values less than 0.05 were accepted as significant.

\section{Results}

Survival. One patient died in the hospital of clinically suspected acute rejection on postoperative day 16 despite maximized immunosuppressive treatment. This child was not considered for retransplantation because of multiorgan dysfunction. A 13-yearold boy with dilated cardiomyopathy and pulmonary hypertension died suddenly at home 4 months after the operation after repeated episodes of biopsy-proved acute rejection. A 12-year-old girl died of severe heart failure in another institution 2 years after transplantation after progressive chronic cardiac rejection confirmed by autopsy. In this patient the native heart tolerated the donor heart dysfunction for some time while the patient waited for retransplantation. Three patients $(25 \%)$ had lobar collapse after transplantation-the right middle lobe, the right upper lobe, and both lower lobes, respectively. The first two were successfully managed conservatively. The third patient, who had also undergone sternal stenting immediately after the operation, required late reintubation and tracheostomy before being uneventfully extubated 2 weeks later.
Within the first 3 postoperative months, an average of 1.3 rejection episodes per patient necessitated intensified immunosuppressive therapy.

Actuarial 1-year survival for the group was $83.3 \%$ (Fig. 4). All nine survivors are active and growing normally at a mean follow-up of 2.2 years (range 11 months to 4.75 years).

Postoperative cardiac catheterization in seven long-term survivors with preoperative pulmonary hypertension showed a significant drop in pulmonary pressure (Fig. 5 and Table I).

Two-dimensional echocardiographic assessment was performed before discharge and then at 3 months, 6 months, and every year after the operation. The ejection fractions and shortening fractions of the donor and recipient hearts were evaluated at regular intervals did not show any progressive significant difference, with a fairly constant level of performance of both hearts (Fig. 6). Mean shortening fractions of the donor and recipient hearts at 6 months were $39.1 \% \pm$ $4.5 \%$ and $14.5 \% \pm 12.5 \%$, respectively.

Postoperative evolution of donor and recipient left ventricular mass is shown in Fig. 7.

\section{Discussion}

This study has shown that heterotopic heart transplantation, in a specific cohort of children, is feasible and gives good results in the medium term. Although heterotopic heart transplantation is not commonly applied, it continues to account for approximately $10 \%$ of all heart transplantations in our center. 


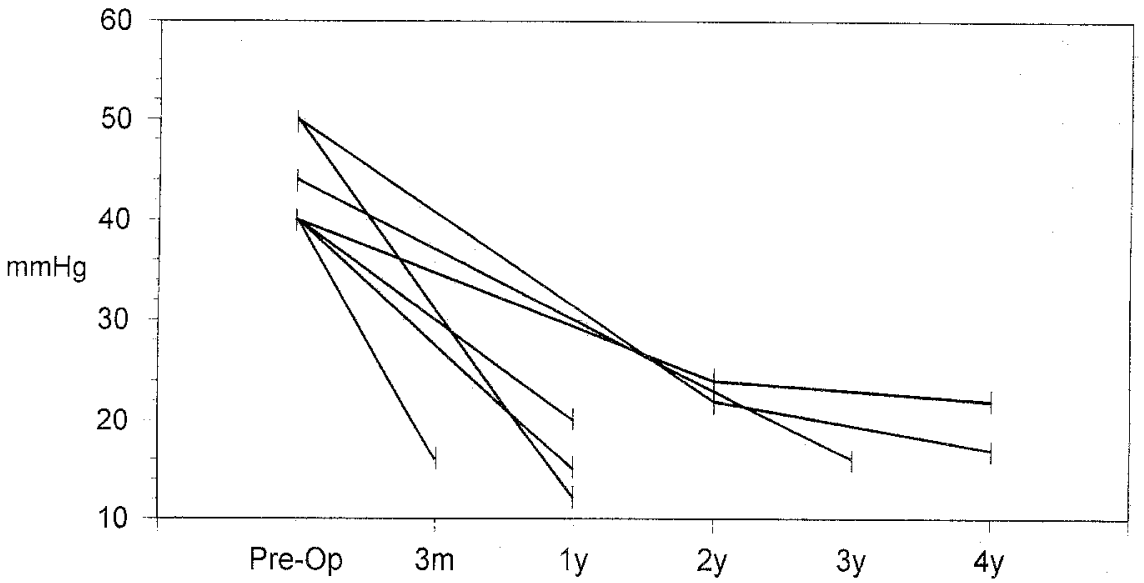

Fig. 5. Postoperative regression of mean pulmonary artery pressure. In patients with preoperative pulmonary hypertension, mean pulmonary artery pressure was reduced after heterotopic transplantation for the duration of follow-up.

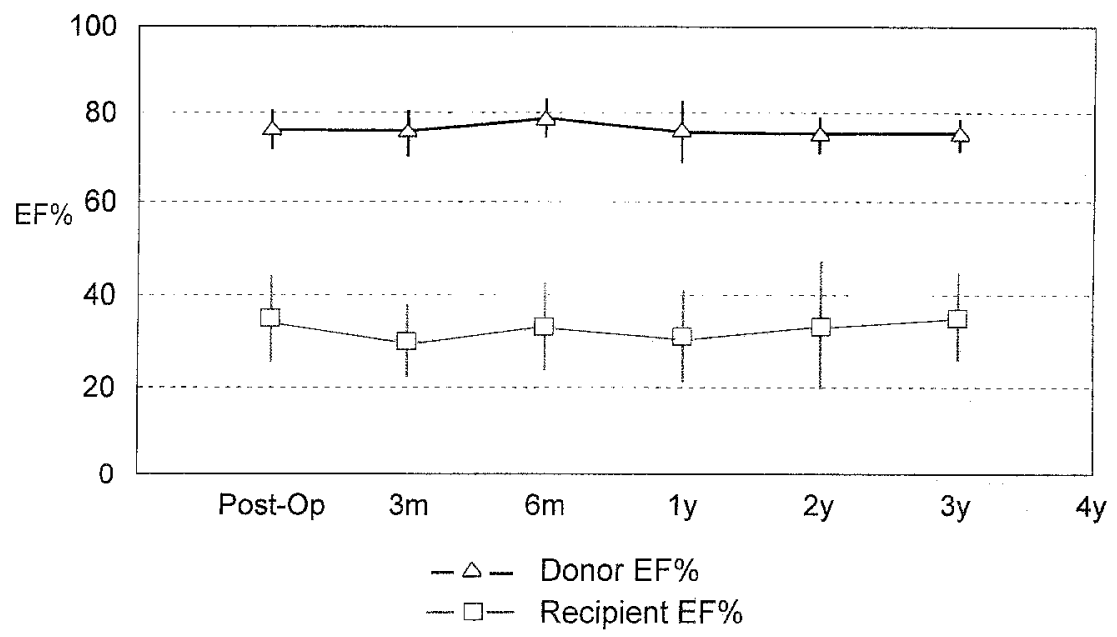

Fig. 6. Ejection fractions $(E F)$ of the donor and recipient hearts were stable for the duration of follow-up.

The main indications for this procedure are (1) presence of fixed high PVR, (2) availability of undersized donor, (3) expectation of a certain degree of recipient heart recovery.

Encouraging results in adults" and in a limited number of children ${ }^{8}$ have led us to expand this program. In theory, this approach has several advantages, which include a better use of donor organs, suitability of the procedure in the presence of

${ }^{*}$ Khaghani A, Dyke C, Santini F, et al. Medium and long term results of heterotopic heart transplantation. Unpublished data. high PVR, patient survival not entirely dependent on the donor organ, and possible recovery of the recipient heart.

However, theoretical disadvantages in children also exist, such as lack of wider experience and data, technical problems related to the size of the thoracic cavity, and doubt about the reversibility of the PVR.

Five children in our group (42\%) underwent heterotopic heart transplantation with a significantly undersized donor. One patient in this subgroup died of severe heart failure 2 years after transplantation, having had progressive chronic cardiac rejection. 


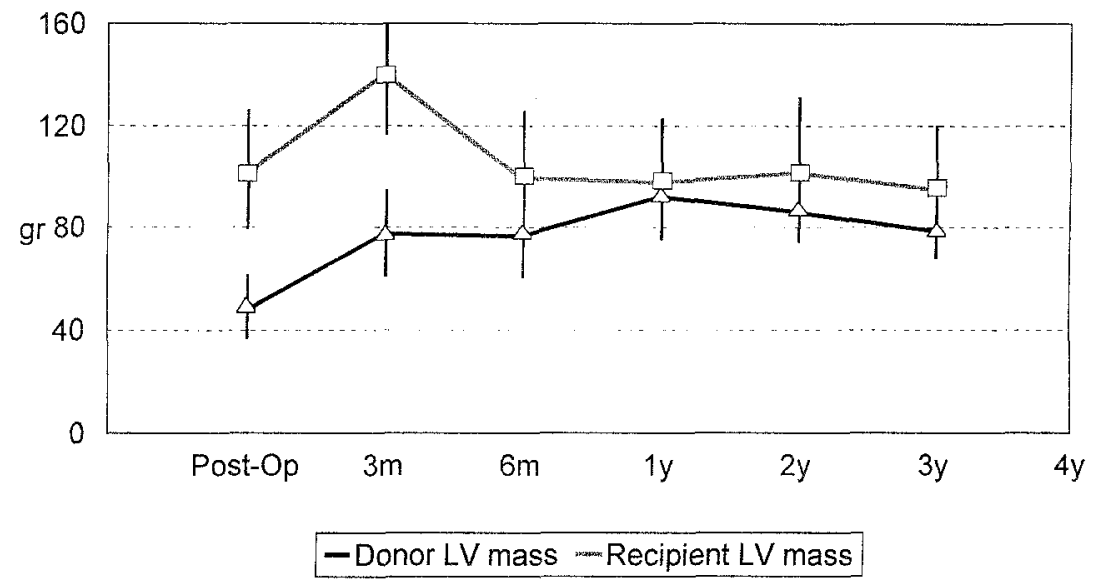

Fig. 7. Left ventricular $(\mathrm{LV})$ mass of the donor and recipient hearts did not change significantly after heterotopic transplantation.

Four of these undersized pediatric donor hearts $(80 \%)$ had previously been rejected for transplantation by one or more other transplant centers for lack of size-matchable recipients (United Kingdom Transplant Support Service Authority, unpublished data). It appears therefore that heterotopic heart transplantation can effectively expand the organ donor pool, decreasing waiting time and waiting time mortality. ${ }^{7}$

A significant increase in mortality after conventional orthotopic transplantation as a result of high PVR and elevated transpulmonary gradient has been documented. ${ }^{15,16}$

Several options have been investigated in the past for this group of recipients, including the use of a larger donor, ${ }^{17}$ domino heart, ${ }^{18,19}$ heart-lung transplantation, ${ }^{20}$ and heterotopic heart transplantation. ${ }^{3}$ Domino or prepared hearts for recipients with pulmonary hypertension have been successfully and extensively used in the adult population. However, the pool of usable domino hearts from the pediatric group is limited. Therefore waiting time for a suitable organ in children often becomes excessive and associated with significant mortality. ${ }^{8}$

Heart-lung transplantation may be an option in children with elevated PVR. However, evidence of an increased incidence of obliterative bronchiolitis in this age group has reduced enthusiasm for the procedure. $^{9-11}$

Seven of eight patients with preoperative pulmonary hypertension in our series are long-term survivors. All but one underwent at least one cardiac catheterization between 3 and 4 years after the operation, which showed in all a progressive and significant drop in pulmonary pressure. The only death in this subgroup occurred suddenly 4 months after the operation after multiple episodes of acute rejection. Also in this patient cardiac catheterization, undergone 3 months before the operation, showed a drop in mean pulmonary pressure from 40 to $16 \mathrm{~mm} \mathrm{Hg}$.

Two children under the age of $2 \frac{1}{2}$ years underwent heterotopic heart transplantation to allow for possible recovery of the recipient heart. One of these patients died during the early postoperative period. The other patient's native heart at 12 months has shown significant improvement with a shortening fraction of more than $25 \%$.

Heterotopic heart transplantation has had little use in the pediatric population, being generally considered inadvisable because of the size limitation of the thoracic cavity in this group. ${ }^{8}$ In our experience the size of the recipient thoracic cavity was not a technical problem. The smallest patient in our series weighed $7.6 \mathrm{~kg}$ at the time of transplantation. However, three patients $(25 \%)$ in our experience had perioperative and early postoperative complications related to pulmonary compression. These events were treated successfully in all, with no recurrence of long-term chest complications. Although no other complications were observed during the follow-up period, the binomial upper confidence bound on zero events in 12 patients is $22 \%$, and we could be missing event rates as high as $22 \%$.

It has been our policy in children to make a diagnosis of acute rejection in the early postoperative period by using noninvasive techniques. Therefore the donor SVC was ligated in the vast majority 
of the patients under 5 years of age with the knowledge based on our previous experience that endomyocardial biopsies are still technically feasible via the recipient right atrium-donor pulmonary artery anastomosis, if needed.

All nine survivors (75\%: mean follow-up 2.2 years) are active children with normal social interactions and satisfactory growth patterns.

In conclusion, we believe that heterotopic heart transplantation warrants consideration and further use in selected pediatric patients, particularly in the presence of secondary pulmonary hypertension, an undersized donor, and the expectation of a certain degree of recipient heart recovery.

\section{REFERENCES}

1. Cooper DKC, Novitsky D, Becerra E, Reichart B. Are there indications for heterotopic heart transplantation? A 2- to 11year follow-up for 49 consecutive patients undergoing heterotopic heart transplantation. Thoracic Cardiovasc Surg 1986;34:300-4

2. Kawaguchi A, Gandjbakhch I, Pavie A, et al. Factors affecting survival after heterotopic heart transplantation. J Thorac Cardiovase Surg 1989;98:928-34.

3. Villaneuva F, Murali S, Uretsky B, et al. Resolution of severe pulmonary hypertension after heterotopic cardiac transplantation. J Am Coll Cardiol 1989;14:1239-43.

4. Nakatani T, Frazier OH, Lammermeir DE, Macris MP, Radovancevic B. Heterotopic heart transplantation: a reliable option for a select group of high risk patients. J Heart Transplant 1989;8:40-7.

5. Rigaud M, Bourdarias JP, El Khoury E, et al. Hemodynamic evaluation of heterotopic heart transplantation. $\mathbf{J}$ Thorac Cardiovasc Surg 1992;95:75-81.

6. Baumgartner WA. Heterotopic transplantation: Is it a viable alternative? Ann Thorac Surg 1992;54:401-2.

7. Sekala ME, Smart FW, Noon GP, Young JB. Attenuation of waiting time mortality with heterotopic heart transplantation. Ann Thorac Surg 1992;54:547-51.

8. Cochrane AD, Adams DH, Radley-Smith R, Khaghani A, Yacoub MH. Heterotopic heart transplantation for elevated pulmonary vascular resistance in pediatric patients. J Heart Lung Transplant 1995;14:296-301.

9. Radley-Smith R, Yacoub M, Pomerance A. Obliterative bronchiolitis is commoner after heart-lung transplantation in younger children [abstract]. J Heart Transplant 1993;12:S69.

10. Whitehead BF, Rees PG, Sorensen K, et al. Results of heart-lung transplantation in children with cystic fibrosis. Eur J Cardiothorac Surg 1995;9:1-6.

11. Adams DH, Cochrane AD, Khaghani A, Smith ID, Yacoub MH. Retransplantation in heart-lung recipients with obliterative bronchiolitis. J Thorac Cardiovasc Surg 1994;107:450-9.

12. Barnard CN, Losman JG. Left ventricular bypass. S Afr Med J 1974;48:303-12.

13. Cowell R, Morris-Thurgood J, Coghlan J, et al. Postoperative hemodynamic improvement with paced linkage of the donor and recipient hearts following heterotopic cardiac transplantation. Clin Cardiol 1994;17:542-6.
14. Kaplan HS, Meier P. Nonparametric estimations from incomplete observations. J Am Stat Assoc 1958;53:457-80.

15. Kirklin JK, Naftel DC, Kirklin JW, et al. Pulmonary vascular resistance and the risk of heart transplantation. J Heart Transplant 1988:7:331-6.

16. Erickson KW, Costanzo-Nordin MR, O'Sullivan EJ, et al. Influence of preoperative transpulmonary gradient on late mortality after orthotopic heart transplantation. J Heart Transplant 1990;9:526-37.

17. Costanzo-Nordin MR, Liao Y, Grusk BB, et al. Oversizing of donor hearts: Beneficial or detrimental? J Heart Transplant 1991;10:717-30.

18. Yacoub MH, Khaghani A, Aravot D, et al. Cardiac transplantation from live donors [abstract]. J Am Coll Cardiol 1988;11:102A.

19. Aravot D, Scott J, Mullins P, et al. Outcome of organs shared in the "domino" procedure. Transplant Proc 1991;23:2612-3.

20. Reitz BA, Wallwork JL, Hunt SA, et al. Heart-lung transplantation: successful therapy for patients with pulmonary vascular disease. N Engl J Med 1982;306:557.

\section{Discussion}

Dr. Charles B. Huddleston (St. Louis, Mo.). It is a privilege to discuss a paper from one of the greatest cardiothoracic units in the world. This review from Harefield addresses a couple of important issues in cardiac transplantation in children. My comments and questions center around the indications for this procedure. For instance, when should heterotopic transplantation be used?

You seem to be classifying two distinct groups as children-small infants and teenagers. Calculating the means of some variables of the two groups as a whole seems a bit misleading. At any rate, without question, donor availability is the most critical issue in cardiac transplantation, and it has driven transplant surgeons treating adults to invade the pediatric-age donor pool for organs to be used in older recipients. It is not at all unusual for them to use a $40 \mathrm{~kg}$ donor in a $70 \mathrm{~kg}$ recipient with a successful outcome. This practice has had a negative impact, however, on the availability of organs for our teenaged recipients. This problem has become evident in our own program recently at St. Louis Children's Hospital. We have five teenagers with status I disease who have been in the pediatric intensive care unit at our hospital for more than 3 months, two of whom are now supported by biventricular assist devices. For a hypothetical $50 \mathrm{~kg}$ recipient, how small a donor would you use in the orthotopic position and how small a donor would you then deem acceptable in a heterotopic position? I envision expanding the donor pool for our teenaged recipients down into the pediatric age range of 5 to 10 years, where not many recipients are currently waiting, as an answer to the problem for the teenagers.

Regarding the elevated PVR indication, all of our potential recipients with an elevated PVR undergo a rigorous evaluation in the catheterization laboratory to test their responsiveness to various pulmonary vasodilators and inotropic agents. With this approach we have performed orthotopic heart transplantations on five children whose initial evaluation would have excluded them on the basis of the standard accepted criteria. All have 
survived, but some have required significant chemical support after transplantation, including inhaled nitric oxide and peripheral vasoconstrictors. Given that this study and others have shown a progressive fall in the PVR and pulmonary artery pressures over time after transplantation, it seems unlikely to me that elevated PVR resulting from heart failure alone would portend a poor long-term prognosis. What sort of pretransplantation evaluation of the pulmonary hemodynamics is done at Harefield?

Finally, one of your stated indications for this approach is the potential recovery of native cardiac function. I agree that this may occasionally happen and that there are certain predictors of this, such as very young age. It is a tribute to the staff of Harefield that you have been able to perform this challenging procedure in such small children. My question is this: Have there in fact been any patients whose native heart function has recovered? If so, would you consider a transplant cardiectomy so that they would no longer need immunosuppressants? I would remind you, and I am sure this is something that you have already thought of, that you could then potentially use that donor heart again in another recipient.

Dr. Santini. Dr. Huddleston, thank you for your comments. Regarding the size of the donor, the smallest donor successfully used in our experience had a weight ratio to the recipient of 0.5 . This was a 16-year-old recipient with pulmonary hypertension. Thus I would say that a donor who is half the weight of the recipient can still be used for heterotopic transplantation. However, I would not be happy to use the heart from a $25 \mathrm{~kg}$ donor for a $50 \mathrm{~kg}$ recipient in the orthotopic position.

oncerning the assessment of PVR in our recipients, all of the patients who have been studied in the catheterization laboratory have been given oxygen, isoprenaline, and nitroprusside to test pulmonary vascular reactivity. For those patients with resistant pulmonary hypertension, postoperative right heart dysfunction still remains a major concern after conventional orthotopic heart transplantation. I do agree, however, that elevated PVR resulting from heart failure alone carries a better prognosis than PVR related to an Eisenmenger complex.

Regarding the recovery of the native heart, in the pediatric population after heterotopic transplantation, the recipient heart function not only did not deteriorate but also showed a degree of improvement in some cases. I think it is conceivable that later on this improvement may allow an eventual explantation of the donor heart. The possibility of using this donor heart again is an interesting idea that we have not tested yet.

\section{Availability of Journal back issues}

As a service to our subscribers, copies of back issues of The Journal of Thoracic and Cardiovascular Surgery for the preceding 5 years are maintained and are available for purchase from Mosby at a cost of $\$ 15.00$ per issue until inventory is depleted. The following quantity discounts are available: $25 \%$ off on quantities of 12 to 23 , and one third off on quantities of 24 or more. Please write to Mosby-Year Book, Inc., Subscription Services, 11830 Westline Industrial Drive, St. Louis MO 63146-3318, or call 800-453-4351 or 314-453-4351 for information on availability of particular issues. If unavailable from the publisher, photocopies of complete issues may be purchased from UMI, 300 N. Zeeb Rd., Ann Arbor, MI 48106, 313-761-4700. 